\title{
Association between $X R C C 1$ polymorphisms and laryngeal cancer susceptibility in a Chinese sample population
}

\author{
W.Q. Wu1 ${ }^{1}$ L.S. Zhang ${ }^{2}$, S.P. Liao ${ }^{1}$, X.L. Lin ${ }^{1}$, J. Zeng ${ }^{3}$ and D. Du ${ }^{1}$ \\ ${ }^{1}$ Department of Health management, \\ The Second Medical College of Jinan University, \\ Shenzhen People's Hospital, Shenzhen, China \\ ${ }^{2}$ Otolaryngological Department, \\ Zhumadian Central Hospital of Henan Province, Zhumadian, China \\ ${ }^{3}$ Central Laboratory, Shenzhen People's Hospital, Shenzhen, China \\ Corresponding author: D. Du \\ E-mail: 13922801116@163.com
}

Genet. Mol. Res. 15 (4): gmr. 15048525

Received February 2, 2016

Accepted May 24, 2016

Published October 5, 2016

DOI http://dx.doi.org/10.4238/gmr.15048525

Copyright (C) 2016 The Authors. This is an open-access article distributed under the terms of the Creative Commons Attribution ShareAlike (CC BY-SA) 4.0 License.

\begin{abstract}
Laryngeal cancer is the major malignant tumor affecting the upper respiratory tract. Previous studies have reported on the association between XRCC1 genetic polymorphisms and risk of laryngeal cancer, but with conflicting results. In this study, we attempted to assess the association between XRCC1 Arg194Trp, Arg280His and Arg399Gln polymorphisms and risk of laryngeal cancer in a Chinese population. A total of 126 laryngeal cancer patients and 254 control subjects were recruited to this study from the Second Medical College of Jinan University between December 2013 and May 2015. The XRCC1 Arg194Trp, Arg280His, and Arg399Gln polymorphic sites were genotyped by polymerase chain reaction-restriction fragment
\end{abstract}


length polymorphism. Our results revealed a significant association between the AA genotype of XRCCl Arg280His [odds ratio (OR) $=2.51,95 \%$ confidence interval $(\mathrm{CI})=1.29-4.87, \mathrm{P}=0.01]$ and an increased risk of laryngeal cancer susceptibility compared to the GG genotype. Moreover, the A allele showed a higher risk of laryngeal cancer susceptibility compared to the $\mathrm{G}$ allele $(\mathrm{OR}=1.63,95 \% \mathrm{CI}=$ $1.19-2.50, \mathrm{P}=0.002$ ). In conclusion, the results of our study suggest that the AA genotype and A allele of the XRCC1 Arg280His polymorphism are associated with an increased laryngeal cancer risk in a Chinese population.

Key words: XRCC1; Arg194Trp; Arg280His; Arg399Gln; Polymorphism; Laryngeal cancer

\section{INTRODUCTION}

Laryngeal cancer is the major malignant tumor affecting the upper respiratory tract, with approximately 156,000 new laryngeal cancer patients and 83,000 deaths from laryngeal cancer in 2012 worldwide (IARC, 2012). The incidence of laryngeal cancer varies considerably across different populations, suggesting that many environmental and lifestyle risk factors are involved in laryngeal cancer development, such as exposure to carcinogens in the work environment, and infection with human papilloma virus and Epstein-Barr virus (Pöschl et al., 2004; La Vecchia et al., 2008). In fact, many studies have indicated that heritable factors contribute to the development of laryngeal cancer, including methylene tetrahydrofolate reductase, epidermal growth factor-like domain 7/Egfl7, necleotide excision repair pathway gene, matrix metallopreteinases 11, P14, B-cell translocation gene 1, special AT-rich sequencebinding protein 1 and 2, DNA repair gene and cyclin-dependent kinase (Wang et al., 2014; Sun et al., 2015; Li et al., 2015; Jiang et al., 2015; Mansour et al., 2016; Li et al., 2016; Bednarek et al., 2016).

It is reported that repair of DNA damage is under genetic control and DNA repair genes contribute to maintaining genome integrity and preventing the development of cancer (Xing et al., 2002; Hu et al., 2016). XRCC1 is the first mammalian gene to be isolated that displays cellular sensitivity to ionizing radiation (Thompson et al., 1990). Three common polymorphisms (single nucleotide polymorphisms) in XRCC1, including Arg 194Trp, Arg280His and Arg399Gln, have been previously elucidated by many studies (Shen et al., 2000; Stern et al., 2001). Additionally, several epidemiologic studies have shown conflicting results on the relationship between $X R C C 1$ genetic polymorphisms and laryngeal cancer risk, but with conflicting results (Gajecka et al., 2005; Yang et al., 2008; Krupa et al., 2011; Ayiheng and Bogela, 2013). We attempted to assess the association between XRCC1 Arg194Trp, Arg280His and Arg399Gln polymorphisms and risk of laryngeal cancer in a Chinese population.

\section{MATERIAL AND METHODS}

\section{Subjects}

Here, a total of 126 patients with laryngeal cancer were consecutively collected from

Genetics and Molecular Research 15 (4): gmr.15048525 
the Second Medical College of Jinan University, China, between December 2013 and May 2015. The diagnosis of laryngeal cancer was pathologically confirmed in all patients.

During the same period, a total of 254 healthy subjects were randomly selected for this study from among individuals who received a regular health check-up at the Second Medical College of Jinan University. Individuals with a history of cancers, end-stage renal or liver disease, malnutrition were excluded from this study. The study design was approved by the Second Medical College of Jinan University. Written informed consent was obtained from all laryngeal cancer patients and control subjects.

\section{Genotyping}

Peripheral blood $(5 \mathrm{~mL})$ was collected from each participant. DNA was extracted from the blood samples using the QIAamp DNA Blood Mini Kit (Qiagen, Venlo, Netherlands). The Arg194Trp, Arg280His, and Arg399GIn polymorphic sites in XRCC1 were genotyped by polymerase chain reaction-restriction fragment length polymorphism (PCR-RFLP). The forward and reverse primer sequences for the Arg194Trp, Arg280His, and Arg399Gln polymorphic sites were 5'-GCCAGGGCCCCTCCTTCAA-3' and 5'-TACCCTCAGACCCACGA GT-3', 5'-GCCCCGTCCCAGGTA-3' and 5'-AGCCCCAAGACCCTTTCACT-3' (Arg195Trp), 5'-CCAGTGGTGCTAACCTAATC-3' and 5'-CACTCAGCACCACTACCACA-3', and 5'-CCCCAAGTACAGCCAGGTC-3' and 5'-TGTCCCGCTCCTCTCAGTAG-3', respectively. The conditions of PCR were set as follows: one cycle of initial denaturation at $94^{\circ} \mathrm{C}$ for 5 min; 35 cycles of denaturation at $94^{\circ} \mathrm{C}$ for $45 \mathrm{~s}$, annealing at $60^{\circ} \mathrm{C}(\mathrm{Arg} 194 \mathrm{Trp}), 69.5^{\circ} \mathrm{C}$ (Arg280His), or $61^{\circ} \mathrm{C}(\operatorname{Arg} 399 \mathrm{Gln})$ for $30 \mathrm{~s}$, and extension at $72^{\circ} \mathrm{C}$ for $45 \mathrm{~s}$; and a final one cycle of extension at $72^{\circ} \mathrm{C}$ for $7 \mathrm{~min}$. RFLP was performed using the restriction enzymes $P v u \mathrm{II}$, $R s a \mathrm{I}$, and MspI for the XRCC1 Arg194Trp, Arg280His, and Arg399Gln polymorphisms, respectively. The restriction enzyme products was performed by $2 \%$ agarose gel electrophoresis for $45 \mathrm{~min}$, and observed under gel imaging system.

\section{Statistical analysis}

Agoodness-of-fit $\chi^{2}$-test was performed to identify and evaluate the probable deviations of the XRCC1 Arg194Trp, Arg280His, and Arg399Gln polymorphisms from the HardyWeinberg equilibrium (HWE). Relationships between the XRCC1 Arg194Trp, Arg280His, and Arg399Gln genetic polymorphisms and laryngeal cancer susceptibility were calculated by multiple logistic regression analyses, and odds ratios (OR) and their $95 \%$ confidence intervals (CIs) were taken to express the results. $\mathrm{P}<0.05$ was considered to be statistically significant for all analyses. All statistical analyses were performed on the SPSS Statistics program for Windows (v.18.0; IBM, Armonk, NY, USA).

\section{RESULTS}

Our analyses revealed that laryngeal cancer patients were of a more advanced age $(t=$ $1.85, \mathrm{P}=0.03)$, had a family history of cancer $\left(\chi^{2}=7.85, \mathrm{P}=0.005\right)$, were males $\left(\chi^{2}=10.31\right.$, $\mathrm{P}=0.001)$, and were habitual tobacco smokers $\left(\chi^{2}=5.14, \mathrm{P}=0.02\right)$ or alcohol consumers $\left(\chi^{2}\right.$ $=20.29, \mathrm{P}<0.001)$ compared to the control subjects (Table 1$)$. With respect to the TNM stage, $79(62.70 \%)$ patients had tumors at stage I-II and $47(37.30 \%)$ had tumors at stage III+IV.

Genetics and Molecular Research 15 (4): gmr.15048525 
Table 1. Demographic and lifestyle characteristics of study subjects.

\begin{tabular}{|c|c|c|c|c|c|c|}
\hline Variables & Patients $(\mathrm{N}=126)$ & $\%$ & Controls $(\mathrm{N}=254)$ & $\%$ & $\chi^{2}$ or $t$ test & $\mathrm{P}$ value \\
\hline Age, years & $57.53 \pm 9.43$ & & $55.46 \pm 10.65$ & & 1.85 & 0.03 \\
\hline \multicolumn{7}{|l|}{ Gender } \\
\hline Males & 99 & 78.57 & 158 & 62.20 & & \\
\hline Females & 27 & 21.43 & 96 & 37.80 & 10.31 & 0.001 \\
\hline BMI, $\mathrm{kg} / \mathrm{m}^{2}$ & $24.64 \pm 2.42$ & & $24.21 \pm 2.55$ & & 1.57 & 0.06 \\
\hline \multicolumn{7}{|c|}{ Tobacco smoking } \\
\hline No & 47 & 37.30 & 126 & 49.61 & & \\
\hline Yes & 79 & 62.70 & 128 & 50.39 & 5.14 & 0.02 \\
\hline \multicolumn{7}{|c|}{ Alcohol consumption } \\
\hline No & 42 & 33.33 & 147 & 57.87 & & \\
\hline Yes & 84 & 66.67 & 107 & 42.13 & 20.29 & $<0.001$ \\
\hline \multicolumn{7}{|c|}{ Family history of cancer } \\
\hline No & 110 & 87.30 & 242 & 95.28 & & \\
\hline Yes & 16 & 12.70 & 12 & 4.72 & 7.85 & 0.005 \\
\hline \multicolumn{7}{|l|}{ Tumor stage } \\
\hline $\mathrm{I}+\mathrm{II}$ & 79 & 62.70 & & & & \\
\hline III+IV & 47 & 37.30 & & & & \\
\hline
\end{tabular}

We observed significant differences in the genotype frequencies of the XRCC1 $\operatorname{Arg} 280 \mathrm{His}\left(\chi^{2}=9.32, \mathrm{P}=0.01\right)$ polymorphisms between the laryngeal cancer patients and control subjects; however, the genotype frequencies of XRCC1 $\operatorname{Arg} 194 \operatorname{Trp}\left(\chi^{2}=0.68, \mathrm{P}=\right.$ $0.71)$ and $\operatorname{Arg} 399 \mathrm{Gln}\left(\chi^{2}=0.35, \mathrm{P}=0.84\right)$ did not differ significantly between the case and control subjects (Table 2). The goodness-of-fit chi-square test revealed that the genotypes of the XRCC1 Arg194Trp, Arg280His, and Arg399Gln polymorphisms in the laryngeal cancer patients ( $\mathrm{P}$ values $=0.86,0.57$, and 0.53 , respectively) and the controls $(\mathrm{P}$ values $=0.99,0.33$, and 0.31 , respectively) were according to the HWE.

Table 2. Genotype distributions of XRCC1 Arg194Trp, Arg280His, and Arg399Gln in the laryngeal cancer and control groups.

\begin{tabular}{l|c|c|c|c|c|c|c|c}
\hline XRCCl & Patients & $\%$ & Controls & $\%$ & $\chi^{2}$ test & P value & \multicolumn{2}{|c}{ P for HWE } \\
\cline { 5 - 9 } & & & & & & & \\
\hline Arg194Trp & & & & & & & & \\
\hline CC & 50 & 39.68 & 110 & 43.31 & & & & \\
\hline CT & 58 & 46.03 & 115 & 45.28 & & & & \\
\hline TT & 18 & 14.29 & 30 & 11.81 & 0.68 & 0.71 & 0.86 & 0.99 \\
\hline Arg280His & & & & & & & & \\
\hline GG & 38 & 30.16 & 112 & 44.09 & & & & \\
\hline GA & 60 & 47.62 & 108 & 42.52 & & & & \\
\hline AA & 29 & 23.02 & 34 & 13.39 & 9.32 & 0.01 & 0.57 & \\
\hline Arg399Gln & & & & & & & & \\
\hline GG & 44 & 34.92 & 96 & 37.80 & & & & \\
\hline GA & 58 & 46.03 & 114 & 44.88 & & & 0.31 \\
\hline AA & 24 & 19.05 & 44 & 17.32 & 0.35 & 0.84 & 0.53 & 0.31 \\
\hline
\end{tabular}

HWE, Hardy-Weinberg equilibrium.

The analysis demonstrated that the AA genotype $(\mathrm{OR}=2.51,95 \% \mathrm{CI}=1.29-4.87$, $\mathrm{P}=0.01)$ of $X R C C 1 \mathrm{Arg} 280 \mathrm{His}$ exposed an increased risk of laryngeal cancer compared to the GG genotype (Table 3). Additionally, the analysis revealed that the A allele showed an increased risk of laryngeal cancer susceptibility, compared to the $\mathrm{G}$ allele $(\mathrm{OR}=1.63,95 \% \mathrm{CI}$ $=1.19-2.50, \mathrm{P}=0.002)$. However, no significant association was found between the XRCC1 Arg194Trp and Arg399Gln polymorphisms and laryngeal cancer susceptibility.

Genetics and Molecular Research 15 (4): gmr.15048525 
Table 3. Relationship between XRCC1 Arg194Trp, Arg280His, and Arg399Gln polymorphisms and laryngeal cancer susceptibility.

\begin{tabular}{|c|c|c|c|c|c|c|}
\hline$X R C C 1$ & Patients & $\%$ & Controls & $\%$ & OR $(95 \% \mathrm{CI})^{1}$ & $\mathrm{P}$ value \\
\hline \multicolumn{7}{|c|}{ Arg194Trp } \\
\hline $\mathrm{CC}$ & 50 & 39.68 & 110 & 43.31 & 1.0 (Reference) & - \\
\hline $\mathrm{CT}$ & 58 & 46.03 & 115 & 45.28 & $1.11(0.68-1.81)$ & 0.66 \\
\hline TT & 18 & 14.29 & 30 & 11.81 & $1.32(0.63-2.71)$ & 0.42 \\
\hline \multicolumn{7}{|l|}{ Allele } \\
\hline $\mathrm{C}$ & 158 & 65.86 & 335 & 65.95 & 1.0 (Reference) & - \\
\hline $\mathrm{T}$ & 94 & 37.31 & 175 & 34.45 & $1.14(0.82-1.58)$ & 0.42 \\
\hline \multicolumn{7}{|c|}{ Arg280His } \\
\hline GG & 38 & 30.16 & 112 & 44.09 & 1.0 (Reference) & - \\
\hline GA & 59 & 46.83 & 108 & 42.52 & $1.43(0.85-2.40)$ & 0.15 \\
\hline AA & 29 & 23.01 & 34 & 13.39 & $2.51(1.29-4.87)$ & 0.01 \\
\hline \multicolumn{7}{|l|}{ Allele } \\
\hline G & 135 & 53.58 & 332 & 65.35 & 1.0 (Reference) & - \\
\hline $\mathrm{A}$ & 117 & 46.43 & 176 & 34.65 & $1.63(1.19-2.50)$ & 0.002 \\
\hline \multicolumn{7}{|c|}{ Arg399Gln } \\
\hline GG & 44 & 34.92 & 96 & 37.80 & 1.0 (Reference) & - \\
\hline GA & 58 & 46.03 & 114 & 44.88 & $1.11(0.67-1.84)$ & 0.67 \\
\hline AA & 24 & 19.05 & 44 & 17.32 & $1.19(0.61-2.29)$ & 0.58 \\
\hline \multicolumn{7}{|l|}{ Allele } \\
\hline G & 146 & 57.94 & 306 & 60.24 & 1.0 (Reference) & - \\
\hline A & 106 & 42.07 & 202 & 39.76 & $1.10(0.80-1.51)$ & 0.54 \\
\hline
\end{tabular}

${ }^{1}$ Adjusted for age, gender, tobacco smoking, alcohol drinking, and family history of cancer. OR, odds ratio; CI, confidence interval.

\section{DISCUSSION}

In the present study, we analyze the association between the XRCC1 Arg194Trp, Arg280His, and Arg399Gln polymorphisms and laryngeal cancer risk; the results of this study indicated the AA genotype and A allele of XRCC1 Arg280His were correlated with a higher risk of laryngeal cancer.

So far, several studies have reported on the association between $X R C C 1$ polymorphisms and development of several types of cancers, including non-small cell lung cancer, gastric cancer, cervical cancer, hepatocellular carcinoma, pancreatic cancer, ovarian cancer, colorectal cancer, and thyroid cancer (Liu et al., 2012; Abdel-Fatah et al., 2013; Feng et al., 2014; Wang and Ai, 2014; Xia et al., 2014; Cătană et al., 2015; Han et al., 2015; Huang et al., 2015; Xu et al., 2015; Zhao and Chen, 2015; Ghosh et al., 2016). Liu et al. (2015) observed a significant relationship between the XRCC1 Arg399Gln polymorphism and risk of cervical cancer in a meta-analysis comprising 2051 cervical cancer patients and 2919 control subjects. Han et al. (2015) reported, in a case-control study comprising 245 patients with non-small cell lung cancer and 257 healthy controls, that the XRCC1 Arg399Gln polymorphism influences cancer risk in a Chinese population. Xu et al. (2015) observed a significant association between the XRCC1 Arg280His polymorphism and risk of hepatocellular carcinoma in a meta-analysis comprising 1848 patients with hepatocellular carcinoma and 1969 controls. However, Liu et al. (2012) reported the lack of any association between the XRCC1 Arg399Gln polymorphism and gastric cancer risk, based on a meta-analysis comprising 3278 gastric cancer patients and 6243 controls. These studies have shown that the XRCC1 polymorphisms may play an important role in imparting susceptibility to cancer development.

However, previous studies analyzing the correlation between XRCC1 gene 
polymorphisms and laryngeal cancer susceptibility have reported conflicting results (Varzim et al., 2003; Gajecka et al., 2005; Yang et al., 2008; Krupa et al., 2011; Ayiheng and Bogela, 2013; Li et al., 2016). Yang et al. (2008) observed, in a study with 72 patients with laryngeal squamous carcinoma and 72 controls in a Chinese population, that the XRCC1 Arg399Gin polymorphism might lead to an increased risk of laryngeal carcinoma. Ayiheng and Bogela (2013) reported, in a study with 60 patients with laryngeal squamous carcinoma and 120 healthy controls, that the XRCC1 Arg399Gln polymorphism may be an independent biomarker for laryngeal cancer susceptibility. However, several studies have reported inconsistent results (Varzim et al., 2003; Krupa et al., 2011; Gajecka et al., 2005). Varzim et al. (2003), Gajecka et al. (2005) and Krupa et al. (2011) reported that the XRCC1 polymorphisms may not be associated with laryngeal cancer risk in a Polish population. On the other hand, Li et al. (2016) reported, based on the results of a meta-analysis comprising 2242 laryngeal cancer patients and 3811 controls, that the XRCC1 Arg399Gln polymorphism might contribute to laryngeal cancer susceptibility and Chen et al. (2014), in another meta-analysis with 1654 laryngeal cancer patients and 2377 cancer-free controls, suggested the lack of an association between the XRCC1 Arg399GIn polymorphism and laryngeal cancer risk. In this study, we discovered a possible correlation between the XRCC1 Arg280His polymorphism and the risk of developing laryngeal cancer. One limitation should be considered in this study. All patients and controls were selected from a single hospital; therefore, the sample may not be representative of the general population, thereby introducing selection bias into this study.

In conclusion, we suggest that individuals harboring the AA genotype and A allele of XRCC1 Arg280His are associated with an increased laryngeal cancer risk in a Chinese population. But the XRCC1 Arg194Trp and Arg399Gln genetic polymorphisms did not contribute to the development this cancer.

\section{Conflicts of interest}

The authors declare no conflict of interest.

\section{ACKNOWLEDGMENTS}

We thank for the staffs in the Second Medical College of Jinan University who help us to recruited the patients and controls into our study.

\section{REFERENCES}

Abdel-Fatah T, Sultana R, Abbotts R, Hawkes C, et al. (2013). Clinicopathological and functional significance of XRCC1 expression in ovarian cancer. Int. J. Cancer 132: 2778-2786. http://dx.doi.org/10.1002/ijc.27980

Ayiheng Q and Bogela A (2013). Study on laryngeal cancer related on polymorphism of the Arg399Gln of XRCC1 DNA repair gene in different nationalities in Xinjiang. Lin Chung Er Bi Yan Hou Tou Jing Wai Ke Za Zhi 27: 948-951, 954.

Bednarek K, Kiwerska K, Szaumkessel M, Bodnar M, et al. (2016). Recurrent CDK1 overexpression in laryngeal squamous cell carcinoma. Tumour Biol. http://dx.doi.org/10.1007/s13277-016-4991-4

Cătană A, Pop M, Hincu BD, Pop IV, et al. (2015). The XRCC1 Arg194Trp polymorphism is significantly associated with lung adenocarcinoma: a case-control study in an Eastern European Caucasian group. Onco Targets Ther. 8: 35333538. http://dx.doi.org/10.2147/OTT.S92361

Chen W, Wang ZY, Xu FL, Wu KM, et al. (2014). Association of XRCC1 genetic polymorphism (Arg399Gln) with laryngeal cancer: a meta-analysis based on 4,031 subjects. Tumour Biol. 35: 1637-1640. http://dx.doi.org/10.1007/ s13277-013-1225-x

Genetics and Molecular Research 15 (4): gmr.15048525 
Feng YZ, Liu YL, He XF, Wei W, et al. (2014). Association between the XRCC1 Arg194Trp polymorphism and risk of cancer: evidence from 201 case-control studies. Tumour Biol. 35: 10677-10697. http://dx.doi.org/10.1007/s13277$\underline{014-2326-\mathrm{x}}$

Gajecka M, Rydzanicz M, Jaskula-Sztul R, Wierzbicka M, et al. (2005). Reduced DNA repair capacity in laryngeal cancer subjects. A comparison of phenotypic and genotypic results. Adv. Otorhinolaryngol. 62: 25-37.

Ghosh S, Ghosh S, Bankura B, Saha ML, et al. (2016). Association of DNA repair and xenobiotic pathway gene polymorphisms with genetic susceptibility to gastric cancer patients in West Bengal, India. Tumour Biol. [Epub ahead of print]

International Agency for Research on Cancer IARC (2012). GLOBOCAN 2012: Estimated Cancer Incidence, Mortality and Prevalence Worldwide in 2012. Available at [http://globocan.iarc.fr/Pages/fact_sheets_population.aspx]. Accessed October 1, 2015.

Han JC, Zhang YJ and Li XD (2015). Association between polymorphisms in the XRCC1 gene and the risk of non-small cell lung cancer. Genet. Mol. Res. 14: 12888-12893. http://dx.doi.org/10.4238/2015.October.21.9

Hu HQ, Wang F, Du X, Zhao XZ, et al. (2016). Genetic variability of XRCC1 influences the treatment outcome of gastric cancer. Genet. Mol. Res. 15: 15. http://dx.doi.org/10.4238/gmr.15017452

Huang Y, Li X, He J, Chen L, et al. (2015). Genetic polymorphisms in XRCC1 genes and colorectal cancer susceptibility. World J. Surg. Oncol. 13: 244. http://dx.doi.org/10.1186/s12957-015-0650-2

Jiang R, Hu W, Sun G, Wang J, et al. (2015). Expression of BTG1 protein in laryngeal squamous cell carcinoma and its clinical significance. Lin Chung Er Bi Yan Hou Tou Jing Wai Ke Za Zhi 29: 1447-1450.

Krupa R, Kasznicki J, Gajęcka M, Rydzanicz M, et al. (2011). Polymorphisms of the DNA repair genes XRCC1 and ERCC4 are not associated with smoking- and drinking-dependent larynx cancer in a Polish population. Exp. Oncol. 33: 55-56.

La Vecchia C, Zhang ZF and Altieri A (2008). Alcohol and laryngeal cancer: an update. Eur. J. Cancer Prev. 17: 116-124. http://dx.doi.org/10.1097/CEJ.0b013e3282b6fd40

Li F, Wang J and Chen M (2016). Single nucleotide polymorphisms in DNA repair genes and the risk of laryngeal cancer: A meta-analysis. Biomed. Pharmacother. 78: 92-100. http://dx.doi.org/10.1016/j.biopha.2015.12.019

Li Z, Ding S, Zhong Q, Li G, et al. (2015). Significance of MMP11 and P14(ARF) expressions in clinical outcomes of patients with laryngeal cancer. Int. J. Clin. Exp. Med. 8: 15581-15590.

Liu BM, Liu TM, You BS, You HY, et al. (2012). Lack of an association between the XRCC1 Arg399Gln polymorphism and gastric cancer based on a meta-analysis. Genet. Mol. Res. 11: 3852-3860. http://dx.doi.org/10.4238/2012. November.12.2

Liu DY, Liang HC and Xiao XM (2015). Association between the XRCC1 Arg399Gln polymorphism and risk of cervical carcinoma: a meta-analysis. Genet. Mol. Res. 14: 9821-9828. http://dx.doi.org/10.4238/2015.August.19.15

Mansour MA, Hyodo T, Akter KA, Kokuryo T, et al. (2016). SATB1 and SATB2 play opposing roles in c-Myc expression and progression of colorectal cancer. Oncotarget 7: 4993-5006.

Pöschl G, Stickel F, Wang XD and Seitz HK (2004). Alcohol and cancer: genetic and nutritional aspects. Proc. Nutr. Soc. 63: 65-71. http://dx.doi.org/10.1079/PNS2003323

Shen H, Xu Y, Qian Y, Yu R, et al. (2000). Polymorphisms of the DNA repair gene XRCC1 and risk of gastric cancer in a Chinese population. Int. J. Cancer 88: 601-606. http://dx.doi.org/10.1002/1097-0215(20001115)88:4<601::AIDIJC13>3.0.CO;2-C

Stern MC, Umbach DM, van Gils CH, Lunn RM, et al. (2001). DNA repair gene XRCC1 polymorphisms, smoking, and bladder cancer risk. Cancer Epidemiol. Biomarkers Prev. 10: 125-131.

Sun Y, Tan L, Li H, Qin X, et al. (2015). Association of NER pathway gene polymorphisms with susceptibility to laryngeal cancer in a Chinese population. Int. J. Clin. Exp. Pathol. 8: 11615-11621.

Thompson LH, Brookman KW, Jones NJ, Allen SA, et al. (1990). Molecular cloning of the human XRCC1 gene, which corrects defective DNA strand break repair and sister chromatid exchange. Mol. Cell Biol. 10: 6160-6171.

Varzim G, Monteiro E, Silva RA, Fernandes J, et al. (2003). CYP1A1 and XRCC1 gene polymorphisms in SCC of the larynx. Eur. J. Cancer Prev. 12: 495-499. http://dx.doi.org/10.1097/00008469-200312000-00008

Wang C and Ai Z (2014). Association of XRCC1 polymorphisms with thyroid cancer risk. Tumour Biol. 35: 4791-4797. http://dx.doi.org/10.1007/s13277-014-1629-2

Wang ZG, Cui W, Yang LF, Zhu YQ, et al. (2014). Association of dietary intake of folate and MTHFR genotype with breast cancer risk. Genet. Mol. Res. 13: 5446-5451. http://dx.doi.org/10.4238/2014.July.24.24

Xia WF, Ma XP, Li XR, Dong H, et al. (2014). Association study of c. $910 \mathrm{~A}>\mathrm{G}$ and c.1686C $>\mathrm{G}$ polymorphisms in XRCC1 gene with risk of hepatocellular carcinoma in the Chinese population. Genet. Mol. Res. 13: 1314-1322. http://dx.doi. org/10.4238/2014.February.28.3

Genetics and Molecular Research 15 (4): gmr.15048525 
Xing D, Qi J, Miao X, Lu W, et al. (2002). Polymorphisms of DNA repair genes XRCC1 and XPD and their associations with risk of esophageal squamous cell carcinoma in a Chinese population. Int. J. Cancer 100: 600-605. http://dx.doi. org/10.1002/ijc. 10528

Xu W, Liu SA, Li L, Shen ZY, et al. (2015). Association between XRCC1 Arg280His polymorphism and risk of hepatocellular carcinoma: a systematic review and meta-analysis. Genet. Mol. Res. 14: 7122-7129. http://dx.doi. org/10.4238/2015.June.29.5

Yang Y, Tian H and Zhang ZJ (2008). [Association of the XRCC1 and hOGG1 polymorphisms with the risk of laryngeal carcinoma]. Zhonghua Yi Xue Yi Chuan Xue Za Zhi 25: 211-213.

Zhao R and Chen G (2015). Role of GSTP1 Ile105Val and XRCC1 Arg194Trp, Arg280His and Arg399Gln gene polymorphisms in the clinical outcome of advanced non-small cell lung cancer. Int. J. Clin. Exp. Pathol. 8: 1490914916.

Genetics and Molecular Research 15 (4): gmr.15048525 